\title{
Effect of light on the vertical distribution of Pecten maximus larvae
}

\author{
Stein Kaartvedt, Dag Lorents Aksnes, Jorun Karin Egge \\ Department of Marine Biology, University of Bergen, N-5065 Blomsterdalen, Norway
}

\begin{abstract}
The vertical distribution of 4 to $20 \mathrm{~d}$ old scallop Pecten maximus larvae was studied in $4 \mathrm{~m}$ deep plastic bags. A positive correlation was found between the mean depth of the larvae and radiation, and a negative correlation between the vertical dispersion of the larvae and radiation as the larvae tended to press against the bottom of the bag at high radia. tion.
\end{abstract}

Studies of larval populations of pectinids in the wild are few because of the difficulty in differentiating between the veligers of the pectinid species (Gruffydd 1975). Consequently, the vertical distribution of Pecten maximus larvae in the water column is not well known. Cragg (1980) presents results from laboratory observations on swimming behaviour of $P$. maximus larvae. He found that veligers alternately swam up and then sank. In his discussion of swimming behaviour and larval environment, Cragg (1980) infers that this behaviour would tend to keep the larvae in surface waters without restricting them to the top few millimetres. Mason (1983) outlines a behaviour pattern composed of an initial, short period near the seabed, followed by a rise of veligers to the surface layers, and descent to the seabed as the time for metamorphosis approaches. The effect of light is, however, not addressed.

In this note, vertical distribution and diel vertical migration of swimming veligers of Pecten maximus in a semi-natural environment are described. Larvae in the age range 4 to $20 \mathrm{~d}$ after fertilization were studied in $4 \mathrm{~m}$ deep enclosures (plastic bags of $90 \%$ light penetration) with a volume of $12 \mathrm{~m}^{3}$. Water inside the enclosures had the same temperature as surrounding seawater. Throughout the experiment (20 Jul to $10 \mathrm{Sep}$ 1986) the temperature varied between 12.3 and $14.5^{\circ} \mathrm{C}$. The vertical temperature gradient between 1 and $4 \mathrm{~m}$ never exeeded $0.15^{\circ} \mathrm{C}$. The enclosures were filled with water from the laboratory seawater system (supplied from $40 \mathrm{~m}$ depth). Salinity ranged between 33.4 and $34.7 \%$ (upper cm excluded). Maximum observed vertical gradient was $1.25 \%$. The enclosures were provided with phytoplankton grown in separate bags. The phytoplankton bags were subjected to continuous flow (approximately $20 \%$ daily flushing rate) fed by the deep water from the laboratory system, with an additional supply of surface water to assure seeding of surface phytoplankton. Nitrogen concentration in the incoming deep water was approximately 8 to $10 \mu \mathrm{g}$-at $1^{-1}$, and commercial fertilizer was used to give an additional concentration of $15 \mu \mathrm{g}$-at $\mathrm{l}^{-1}$ nitrogen in the incoming water. Vertical mixing in the phytoplankton enclosures was obtained by air-lift.

The larvae bag was filled with deep water, seeded by an inoculum from the phytoplankton bags, and a bloom based on the nutrients in the deep water developed. After hatching of the introduced scallop eggs (see below), phytoplankton culture was added continuously with a flushing rate of the larvae bag of approximately 5 to $10 \% \mathrm{~d}^{-1}$. Both the ingoing and outgoing water was filtered through a screen with a mesh size of $63 \mu \mathrm{m}$. In the first batch studied, the larvae were lost during the second week of the experiment due to malfunction of the filter on the outgoing water. During the second part of the experiment (S2, S3 - see below) therefore, flow through the system was not started until Day 12 after introduction of the fertilized scallop eggs.

Adults of Pecten maximus, stored in water from the laboratory seawater system, were induced to spawn by exposure to surface water. The transfer to surface water involved a temperature increase of approximately 4 to $5^{\circ} \mathrm{C}$. Thermostimulation has been a traditional method of inducing spawning in bivalves (Loosanoff \& Davis 
1963). We were, however, never able to induce spawning in specimens which had been stored in nets in the upper metres by transfer to surface water heated to obtain a corresponding temperature increase. Such specimens would, however, after a period of some weeks in the cold, high salinity deep water from the laboratory seawater system spawn at retransfer to the warmer, less saline surface water. Furthermore, heating of deep water never gave the same spawning success as transfer between the 2 water masses. In nature spawning associated with coastal water mass replacement may be of adaptive value, as shown for fish by Frank \& Leggett (1982).

The eggs were cross-fertilized and then transferred to the enclosures. The bags were initially equipped with a 'false bottom' to prevent the eggs from sinking into the coned bottom of the bag. After larvae reached swimming stage, this false bottom was removed.

Larvae samples were collected at $0,1,2,3$, and $4 \mathrm{~m}$ depth by a 1.51 Ruttner water sampler (Schwoerbel 1966). Two batches of larvae were studied. The first batch was designated S1. It included day and night samples from Day 4 and 8 after fertilization. Results from the second batch are grouped into 2 series. S2 includes day and night samples from Days 8,12 , and 16, while S3 includes results from a total of 13 series of vertical samples taken throughout a diel cycle on Day 20. Daytime samples in S1 and S2 were collected between 1000 and $1400 \mathrm{~h}$ and the corresponding nocturnal samples were collected within $2 \mathrm{~h}$ after sunset.

Although vertical distributions were obtained for different ages of larvae, we have not tried to reveal ontogenetic effects due to the simultaneous changes in other factors (e.g. population density, time spent under

Table 1 Pecten maximus. Regression equations (and regression ANOVA) between mean depth of larvae ( $M D, m)$ and global radiation $\left(\mathrm{R}, 0.01 \mathrm{MJ} \mathrm{m} \mathrm{m}^{-2} \mathrm{~h}^{-1}\right)$ and standard deviation (vertical dispersion, VD) along the depth axis (m). All data from Series S1, S2 and S3 are used in the analysis (23 sampling occasions). $r$ : correlation coefficient $F$-values indicate that both regressions are significant at the 0.005 level

\begin{tabular}{|c|c|c|c|c|}
\hline $\begin{array}{l}M D=2.48+0.0056 R_{i} \\
\text { Source of variation }\end{array}$ & $\begin{array}{c}r=0.63 \\
\mathrm{df}\end{array}$ & SS & MS & $F$ \\
\hline Regression & 1 & 2.292 & 2.292 & 13.7 \\
\hline Residual & 21 & 3.507 & 0.167 & \\
\hline Total & 22 & 5.799 & & \\
\hline $\mathrm{VD}=1.23-0.0036 \mathrm{R}$ & $r=0.74$ & & & \\
\hline Source of variation & $\mathrm{df}$ & SS & MS & $F$ \\
\hline Regression & 1 & 0.937 & 0.937 & 25.3 \\
\hline Residual & 21 & 0.776 & 0.037 & \\
\hline Total & 22 & 1.713 & & \\
\hline
\end{tabular}
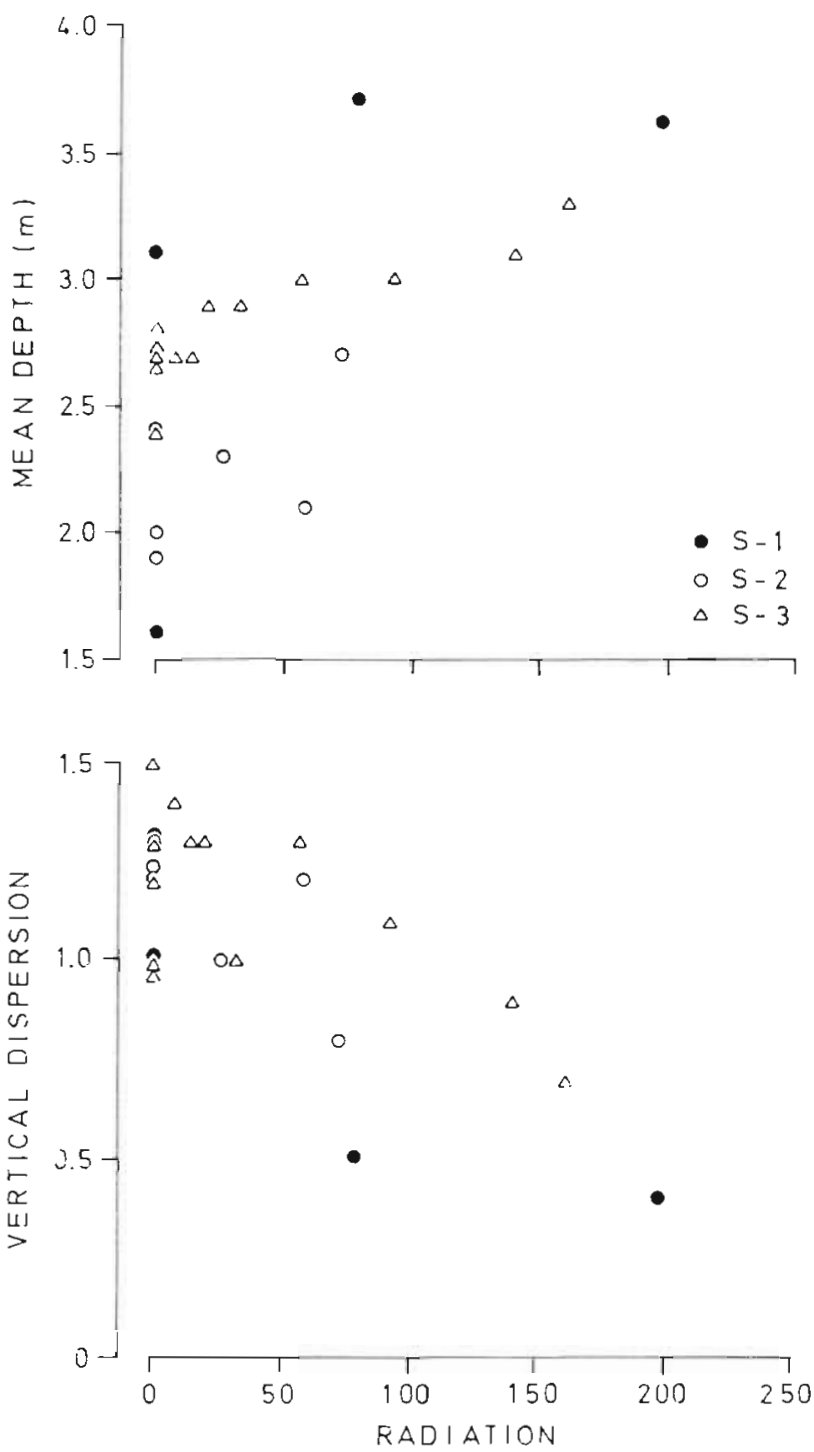

Fig. 1. Pecten maximus. Mean depth and the vertical dispersion (represented as the standard deviation of the vertical distribution along the depth axis [m]) of larvae plotted against radiation (global radiation given as $0.01 \mathrm{MJ} \mathrm{m} \mathrm{m}^{-2} \mathrm{~h}^{-1}$ ) as measured at the Geophysical Institute at the University of Bergen (Anon 1987)

experimental conditions). All data was therefore combined in a single analysis of the relationship between vertical distribution and light. In Fig. 1 the mean depth of the larvae and the standard deviation about the mean depth (which represents vertical dispersion of the larvae along the depth axis) for all sampling occasions are plotted against radiation as measured at the Geophysical Institute at the University of Bergen (situated $20 \mathrm{~km}$ from the experimental site). Fig. 1 indicates a positive correlation between larval mean depth and the amount of incident radiation and a negative corre- 


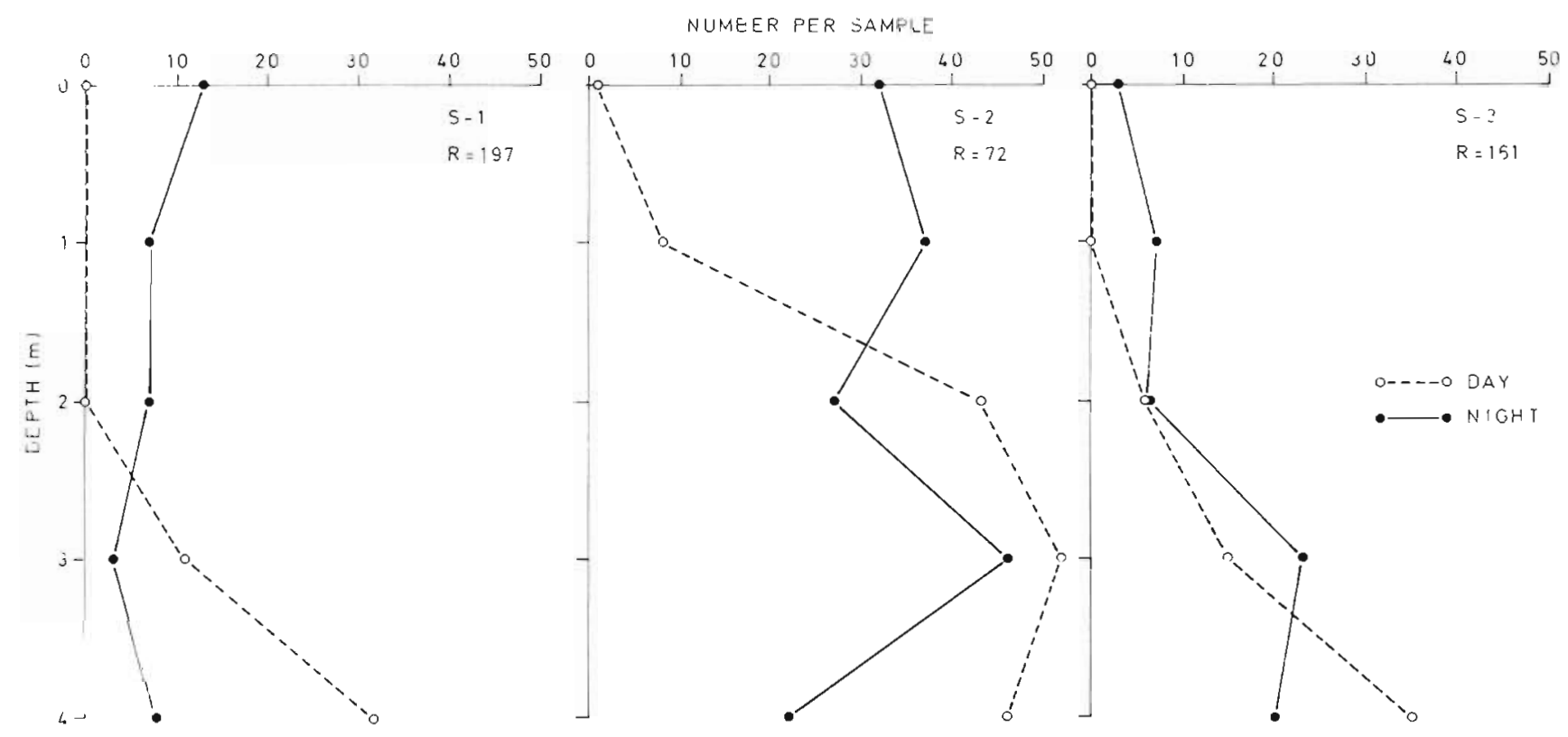

Fig. 2. Pecten maximus. Vertical distribution of larvae (no. $1.51^{-1}$ ) at day and night in Series S1, S2, and S3. R-values give the amount of incident radiation during daytime sampling $\left(0.01 \mathrm{MJ} \mathrm{m}^{-2} \mathrm{~h}^{-1}\right)$. Radiation was zero during sampling at night

lation between vertical dispersion and radiation. Linear regression analysis (with ANOVA) is given in Table 1. For all 23 sampling occasions the radiation measurements accounted for 40 and $55 \%\left(100 \mathrm{r}^{2}\right)$ of the variation in mean depth (MD) and vertical dispersion (VD) (Table 1). The change in vertical dispersion is probably an effect of the finite depth of the plastic bags as the larvae tended to press against the bottom of the bag at high radiation (Fig. 2). This result may therefore solely be an artifact of the procedure. Nevertheless, the reduction of vertical dispersion with increasing light is a usable way of revealing the larval response to light in the present experiment.

In Fig. 2, examples of differences in vertical distribution found between day and night in Series S1, S2 and $\mathrm{S} 3$ are given. In each series, the daytime distribution at the highest radiation found through the experimental period (represented by the point to the far right for each series in Fig. 1) is compared to the corresponding distribution at night. Fig. 2 shows that the larvae were distributed higher in the water column in darkness than in light. To conclude, both Fig. 2 and the regres- sions presented in Fig. 1 and Table 1 clearly indicate that the vertical distribution of Pecten maximus veliger larvae depends on the prevailing light-level.

\section{LITERATURE CITED}

Anon (1987). Radiation observations in Bergen, Norway, 1986. Geophysical Institute, Univ. Bergen

Cragg, S. M. (1980). Swimming behaviour of the larvae of Pecten maximus (L.) (Bivalvia). J. mar. biol. Ass. U.K. 60: $551-564$

Frank, K. T., Leggett, W. C. (1982). Coastal water mass replacement: its effect on zooplankton dynamics and the predatory-prey complex associated with larval capelin (Mallotus villosus). Can. J. Fish. Aquat. Sci. 39: 991-1003

Gruffydd, L. D. (1975). The development of the larvae of Chlamys islandica in the plankton and its salinity tolerance in the laboratory (Lamellibranchia, Pectinida). Astarte 8: $61-67$

Loosanoff, V. L., Davis, H. C. (1963). Rearing of bivalve molluscs. Adv. mar. Biol. 1: 1-136

Mason, J. (1983). Scallop and queen fisheries in the British Isles. Fishing News Books, Famham, England

Schwoerbel, J. (1966). Methoden der Hydrobiologie. Franckh'sche Verlagsbuchhandlung, Stuttgart 